\title{
HISTÓRIAS DE UMA CIDADE E DE SEUS TRABALHADORES EM TEMPOS DE GUERRA: PELOTAS (1914-1918)
}

\author{
STORIES OF A CITY AND OF ITS WORKERS \\ IN WAR TIMES: PELOTAS (1914-1918)
}

DOI: http://dx.doi.org/10.15448/2178-3748.2015.1.19883

\author{
Beatriz Ana Loner \\ Doutora - UFRGS \\ E-mail: bialoner@gmail.com \\ Lorena Almeida Gill \\ Pós-Doutora - UDSS \\ E-mail: lorenaalmeidagill@gmail.com
}

\begin{abstract}
RESUMO: Pelotas foi uma cidade com forte organização operária. Muitos trabalhadores, portanto, estiveram envolvidos na construção de sindicatos e de meios de comunicação, fortalecendo a imprensa, por exemplo, além de promoverem eventos culturais e formativos. Durante a Primeira Guerra Mundial houve um intenso movimento pela paz e pelo antimilitarismo, os quais envolveram, principalmente, trabalhadores organizados, muitos deles anarquistas e algumas mulheres. Pretende-se, neste artigo, abordar a conjuntura na cidade, enfatizando a luta contra a guerra, além de eventos que marcaram aqueles anos, como a gripe espanhola de 1918. Os principais documentos que serão utilizados se vinculam a jornais da época, especialmente, o Diário Popular, órgão do Partido Republicano Rio-Grandense e O Rebate, opositor da Municipalidade.
\end{abstract}

PALAVRAS-CHAVE: Primeira Guerra Mundial. Organização operária. Pelotas.

ABSTRACT: Pelotas was a city with strong workers organization. Lots of them, therefore, were involved in the construction of unions and medias, making stronger the press, for example, besides promoting cultural and formative events. During the First World War, it started a big peace and antimilitarism movement, which has involved, mostly, organized workers, many anarchists and some women. We intend, in this article, to approach the city conjecture, emphasizing the struggle against war, besides the events that were important those years, like the 1918's Spanish flu. The main documents that will be used are those that are linked to the newspapers of the time, specially, the Diário Popular, an organ of Partido Republicano Rio-Grandense, and O Rebate, the opponent in the city.

KEYWORDS: First World War. Workers organization. Pelotas.

A Primeira Guerra Mundial ${ }^{1}$ envolveu vários países, os quais representavam os interesses das grandes potências do momento. Além deles, outras nações, unidas por laços financeiros ou políticos, também se perfilaram em cada um dos lados. Foi considerada,

\footnotetext{
${ }^{1}$ Para saber mais ver, entre outros, Hobsbawm, Eric. Era dos Extremos. O breve século XX (1914-1991). São Paulo: Companhia das Letras, 1995 e Ferro, Marc. História da Primeira Guerra Mundial (1914-1918). Lisboa: Edições 70, 1992.
}

Oficina do Historiador, Porto Alegre, EDIPUCRS, v. 8, n. 1, jan./jun. 2015, p.7-20. 
portanto, uma guerra global tendo como centro a Europa. O Brasil teve participação pouco expressiva no processo. No início do conflito, declarou neutralidade, mas no ano de 1917, em consequência do afundamento de seu navio mercante Paraná, acabou por participar da guerra, a partir de três medidas principais adotadas: abertura dos portos brasileiros aos países aliados; patrulhamento do Atlântico Sul e envio de missão médica à Europa.

Mas, se não participou inicialmente, não quer dizer que o país não sofreu com as consequências do conflito. A frágil produção industrial brasileira era muito dependente da importação de máquinas, peças de reposição e insumos para seu funcionamento e, quando estes produtos deixaram de estar disponível para o país, devido à desorganização da produção europeia, a situação ficou muito difícil para algumas fábricas, que terminaram tendo que diminuir sua produção ou fechar as portas. Com isso, o desemprego e/ou baixos salários afligiram o proletariado durante os anos de guerra. Através de suas associações e atividades, pode-se avaliar o grau de resposta dos trabalhadores organizados a essa situação, que culminou com os episódios de greve geral em 1917 e outras tentativas de paralisação em anos seguintes.

Em Pelotas, a Primeira Guerra Mundial trouxe consequências, especialmente ao movimento dos trabalhadores, o que é publicizado em periódicos do período. Para a composição deste artigo serão utilizadas, principalmente, notícias de jornais. De forma mais específica, notas encontradas no Diário Popular e no $O$ Rebate, o primeiro, jornal da situação borgista na cidade e o segundo, um periódico de oposição. A intenção é a de problematizar o uso da imprensa, através de uma análise densa das notícias publicadas, ao se verificar o conteúdo do jornal, as relações que este possuía com o mercado, o público que queria atingir e quais os objetivos a que se propunha (LUCA, 2010).

\section{Antecedentes}

O começo da industrialização gaúcha se deu a partir da década de 1870, em dois polos principais: Rio Grande-Pelotas e Porto Alegre. Segundo ALONSO, BENETI e BANDEIRA (1994, p. 23): “a capital possuía 4.888 operários e a região sul, 5.082. As duas regiões correspondiam a 2/3 do emprego industrial do Estado".

Oficina do Historiador, Porto Alegre, EDIPUCRS, v. 8, n. 1, jan./jun. 2015, p.7-20. 
Pelotas possuía, principalmente, indústrias de produtos oriundos da pecuária, algumas de grande porte destinadas à exportação e outras dirigidas para o mercado interno. Tal situação esteve vinculada a uma tradição que a cidade construiu de produzir carne salgada, através de mais de 40 charqueadas que se organizaram na região, principalmente no século XIX.

O declínio da região sul e de Pelotas se deu no início do século XX, tendo em vista a crise do principal produto, o charque, que teve problemas, sobretudo, em função da concorrência com a região platina. Além do mais, nas primeiras décadas do século XX, o surgimento de frigoríficos desencadeou uma grave crise nas charqueadas, as quais passaram a ser desativadas pouco a pouco.

De todo modo, como resquício ainda do desenvolvimento obtido entre 1860 e 1890 , que, para Magalhães (1993), foi o período áureo da cidade, havia importantes atividades econômicas na região, o que permitia que Pelotas possuísse, em 1890, 83 indústrias e 18 charqueadas. Contudo, ao longo das quatro décadas da república velha, esta pioneira organização industrial vai sendo desativada, concentrando-se as fábricas, diminuindo sua quantidade e diversidade, com o que se encaminhou para um perfil de cidade que vive da agropecuária e das atividades industriais a ela relacionadas (LONER e AQUINI, 2012, p. 112-115).

\section{Movimentações durante o conflito}

A industrialização pelotense proporcionou que o número de trabalhadores fosse grande durante todo o período e que suas organizações e mobilizações se efetivassem.

Um dos principais problemas dos trabalhadores, antes mesmo do início da guerra, foi a questão da carestia, havendo mobilizações organizadas pelas principais associações de trabalhadores da cidade na época, a União Operária e a Liga Operária, de 1911 a 1913.

Por outro lado, a cidade também sofreu desastres naturais no período, como a grande enchente em 1914, que alagou várias áreas de Pelotas por longos dias, sem que a municipalidade tivesse tratado de compensar seus efeitos sobre os habitantes das regiões mais alagadiças, como a região do Porto, a Várzea que rodeava a cidade e o futuro bairro do

Oficina do Historiador, Porto Alegre, EDIPUCRS, v. 8, n. 1, jan./jun. 2015, p.7-20. 
Fragata, alguns dos locais de moradia das camadas mais pobres da população (LONER, 2001).

Desta forma, explica-se porque um dos primeiros movimentos importantes que aconteceu no período da guerra (1914) foi uma manifestação contra a empresa Ferro Carril, que disponibilizava bondes com tração animal à população. A empresa parou, em um movimento grevista, tendo em vista uma nova concessão realizada pela Intendência Municipal e também pelas críticas que vinha recebendo, sobretudo dos seus usuários.

Segundo Oliveira (1997, p. 27), a mobilização trouxe uma maior insatisfação entre a população, que queimou 27 bondes e se manifestou, através de centenas de pessoas, pelo centro da cidade.

Embora o assunto não tivesse vínculo com a Primeira Guerra, mostrava uma grande capacidade de organização da população em geral e um clima de imensa insatisfação popular, que encontrou na depredação dos bondes um momento de desafogo.

A situação dos trabalhadores pelotenses e pessoas pobres na cidade era muito difícil. Eles trabalhavam em locais insalubres, recebiam pouco e viviam em regiões com escassa ou nenhuma infraestrutura, especialmente em loteamentos que se organizavam nesse momento, a partir da ganância de alguns empresários, que dividiam pequenos terrenos em amplas áreas de terra, fazendo apenas a demarcação das ruas e pouco se importando com questões vinculadas ao saneamento básico (GILL, 2006).

O tema da guerra começou a aparecer fortemente no dia $1^{\circ}$ de janeiro de 1915 , p. 1 , pelas páginas de um periódico. O jornal Diário Popular ${ }^{2}$, órgão do Partido Republicano RioGrandense, o qual estava no poder tanto no Estado quanto na cidade, publicou um texto, assinado por Theophilo Biafra, no qual ele faz uma espécie de avaliação do conflito, assim dizendo:

Mau grado as esperanças que nele depositavam, o ano velho, esse trágico 1914, tantas desgraças trouxe ao mundo, que encheu todas as medidas. Assassinatos, pestes, guerras foram os melhores presentes que à humanidade trouxe e tão farto andou dessas misérias que parte alguma da terra esteve livre de as sentir. Velho ano maldito.

\footnotetext{
${ }^{2}$ O jornal Diário Popular foi fundado em 1890 como órgão oficial de divulgação do Partido Republicano Rio Grandense. Segundo Rüdiger (1993), na virada do século XIX para ao XX se vivia a fase do jornalismo políticopartidário e o periódico Diário Popular era exemplar deste período.
}

Oficina do Historiador, Porto Alegre, EDIPUCRS, v. 8, n. 1, jan./jun. 2015, p.7-20. 
No decorrer do texto, percebe-se um tom de desânimo e melancolia, justamente por não se saber quanto tempo duraria o conflito, quais países abarcariam e as perdas materiais e humanas que trariam. Biafra finaliza da seguinte forma:

Aí vem o ano novo. A mim me sorri a sua novidade. Bom seria que não desse tanto que falar de si como o seu antecessor. Em todo o caso façamos votos para que deixe encerrada essa hecatombe da guerra que nos leva a viver há quinze séculos atrás.

Nos jornais, até mesmo anúncios de remédios faziam referências ao conflito mundial. No dia $1^{\circ}$ de fevereiro de 1916, p. 2, no Diário Popular aparece o seguinte reclame, no qual consta a figura de um soldado com uma arma na mão:

VIDALON - A minha resistência eu devo a esta poderosa arma!! Vidalon, só não é forte quem não quer. É a eliminadora de todos os males. Em todas as farmácias. Depositários no Rio. E. Legey \&C. Rodolpho Hess \& C. Depositários nesta cidade: H. C. Bojunga, rua General Netto, 354.

Entre o operariado, o grupo mais articulado no período da guerra era o dos anarquistas. As greves de 1917 e 1919 tiveram a presença deles do ponto de vista de mobilização e participação. Eram em pequeno número, mas bastante criativos, o que fazia com que aglutinassem em torno deles um expressivo número de trabalhadores.

Em Pelotas, a Sociedade União Operária, vinculada a eles, começou na década de 1910, lutando pelas 8 horas de trabalho. A partir de 1912, sua atuação se transfere da União para outra sociedade, a Liga Operária, da qual conquistam a diretoria e a transformam num ponto de apoio para várias outras associações e atividades implementadas na cidade, desde aquelas reivindicativas, como campanhas e mobilizações, até atividades culturais e educativas. O ponto alto do grupo libertário, no entanto, em termos de manifestações culturais ocorreu nos anos de 1914 e 1915, já que nesse momento, existia em atividade um grupo teatral, banda musical, centro feminino e de jovens, centro de estudos, grupo de pensamento libertário, escola para crianças e ateneu libertário e imprensa (LONER, 2001). Durante os anos de 1915 e 1916, eles publicaram dois semanários de divulgação de suas ideias e constituíram fonte de influência para outros setores sociais, especialmente através da difusão

Oficina do Historiador, Porto Alegre, EDIPUCRS, v. 8, n. 1, jan./jun. 2015, p.7-20. 
de grupos teatrais, embora com conteúdo diverso, entre outros setores, como a comunidade negra pelotense, que voltou a estabelecer grupos teatrais em suas associações ${ }^{3}$.

A greve de 1917, que se colocou fortemente no contexto da Primeira Guerra, ocorreu entre 9 e 17 de agosto ${ }^{4}$ e teve duas estratégias principais: foi enviada circular aos patrões exigindo $25 \%$ de aumento salarial, 8 horas para trabalho masculino e 6 horas para mulheres e crianças. Foram feitas reivindicações relativas à população em geral, como, por exemplo, que: o pão deveria ser vendido a peso, a exigência do tabelamento dos gêneros de primeira necessidade e a diminuição de impostos sobre imóveis (LONER, 2001), acompanhando de perto as principais necessidades da parcela de população assalariada da cidade, que sofria com a carestia e a falta de casas higiênicas e baratas para morar.

Em 1917, os trabalhadores no Brasil já suportavam quatro anos de desemprego, diminuição do salário para quem ainda estava empregado e forte aumento do custo de vida provocado pelas dificuldades causadas pelo conflito. A situação tornou-se insustentável e terminou explodindo numa série de movimentos grevistas de caráter amplo, que estouraram naquele ano, a partir de São Paulo e depois se difundindo por alguns estados, entre eles o Rio Grande do Sul. No RS, houve greve geral em Porto Alegre e um importante movimento paredista entre os ferroviários, com a participação nas negociações do governo estadual, o que trouxe esperanças de alívio aos operários pelotenses (PETERSEN, 2001).

Durante o movimento paredista, vários operários acabaram feridos e houve um morto pela atuação da polícia, que interrompeu a assembleia dos trabalhadores a tiros, realizada na sede da Liga Operária. O enterro do trabalhador assassinado provocou imensa comoção na cidade e um clima de tensão tão forte que originou a vinda de delegação da Federação Operária do Rio Grande do Sul (FORGS) para auxiliar nas negociações, pelo lado do operariado. Pelo governo, veio à cidade e conduziu as tratativas para o encerramento da greve, representante do governador do Estado (LONER, 2001).

Com isso, houve acordos favoráveis à maioria das categorias, com algumas exceções, como as trabalhadoras da tecelagem. O saldo da greve de 1917 foi positivo com aumentos

\footnotetext{
${ }^{3}$ A comunidade negra e trabalhadora de Pelotas dedicou-se muito cedo ao teatro amador, criando associações e grupos teatrais ainda na década de 1890. Entretanto, esta prática havia declinado nestes anos iniciais do século XX e foi revigorada com a influência do teatro anarquista, inclusive com peças de atores negros sendo representadas no palco do salão da Liga Operária, como se está descobrindo em pesquisa ainda inédita de Loner. ${ }^{4}$ Sobre o início do movimento assim é colocado no jornal Diário Popular, de 10 de agosto de 1917, p. 2: “O movimento grevista que, há dias, se vem manifestando no seio de alguns elementos operários, nesta cidade, e que, até então, fora mantido numa atitude ordeira e, por isso, aceitável, de simples recusa ao trabalho, sob a alegação das dificuldades da vida nos dias vigentes, teve ontem, lamentável desvio, acarretando correria ligeiras e incidentes desagradáveis.
}

Oficina do Historiador, Porto Alegre, EDIPUCRS, v. 8, n. 1, jan./jun. 2015, p.7-20. 
salariais e maior organização dos trabalhadores. Quanto às reivindicações sobre o aumento dos preços, foi instituído um tabelamento dos gêneros de primeira necessidade, que, entretanto, não funcionou, retornando a carestia aos seus altos níveis.

Por sua vez, tal situação ensejou uma nova tentativa de greve geral em 1919, que, desta vez, foi reprimida com maior força pelas autoridades, nada conseguindo de positivo. Estes movimentos não foram conduzidos apenas pelos anarquistas, embora eles estivessem na direção de muitos sindicatos. Na greve de 1917, constituiu-se uma comissão popular, com representantes de vários setores para negociar e encaminhar as reivindicações. Mas as práticas libertárias e suas palavras de ordem eram a principal inspiração destes movimentos, que, por sua vez, também refletiam a conjuntura nacional, de greves gerais e mobilizações, bem como a internacional, com as notícias vibrantes e esperançosas (para o grupo) que chegavam da revolução Russa de 1917 e que, naquele momento, ainda era confundida com uma revolução com traços libertários (LONER, 2001).

A revolução russa evoluiu durante o ano de 1917, desde a deposição do Czar em março daquele ano, até a tomada do poder pelos bolcheviques em novembro ${ }^{5}$, pelo calendário gregoriano, utilizado pela maioria dos países ocidentais. Compreende-se, então, que quando houve a greve geral de agosto, em Pelotas, o processo estava em curso e pouquíssimas informações chegavam sobre o que se passava realmente naquele país. Segundo Antunes (2000), a fonte de informações dos jornais locais se dava através de agências noticiosas internacionais e seu viés era moderado, em termos de cobertura jornalística.

Já na greve de 1919, havia uma expectativa que a revolução político-social estivesse em curso mundialmente e que pudesse ser deflagrada também no Brasil, tanto que no movimento deste ano em Porto Alegre, material de muitos sindicatos e da FORGS, como panfletos e jornais, eram datados como "do ano III da revolução social" 6 . Tal fato se constituiu em um dos motivos para que o tratamento dispensado pelos governos fosse muito mais duro e intransigente nos eventos de 1919 do que em 1917, quando houve atividades de negociação entre a comissão de greve, empresários e governo estadual.

A atuação dos libertários em Pelotas construiu um momento muito dinâmico culturalmente nesse período, uma vez que algumas lideranças faziam teatro e eram atores. As

\footnotetext{
${ }^{5}$ Pelo calendário utilizado na Rússia, respectivamente em fevereiro e outubro, pois apenas em 1918 este país aderiu ao calendário gregoriano.

${ }^{6}$ Para saber mais sobre as greves daquele período e suas intenções, são indicadas as seguintes teses ou dissertações, defendidas recentemente: BARTZ (2008 e 2014), QUEIRÓS (2000 e 2012) e OLIVEIRA (2009).
}

Oficina do Historiador, Porto Alegre, EDIPUCRS, v. 8, n. 1, jan./jun. 2015, p.7-20. 
apresentações constavam de quadros cômicos, canções, dramas de fundo social e comédias críticas, cujos temas versavam sobre a crítica da Igreja Católica e a sociedade capitalista, denunciavam a exploração do operariado, com um forte sentido antimilitarista e antiburguês. O teatro era utilizado para a educação dos operários e de suas famílias. ${ }^{7}$ Nos finais de semana eram feitas programações que iniciavam na tarde de sábado ou domingo e se prolongavam até a noite, no sentido de educar e divertir, e ao mesmo tempo, evitar que o trabalhador se envolvesse com a bebida, o jogo, as mulheres e a Igreja.

O Centro Feminino de Estudos Sociais (CFES), com atuação também no período, foi um dos dois únicos grupos femininos a se fazerem representar no Congresso pela Paz no Rio de Janeiro em 1915. O grupo durou menos de um ano, talvez porque muitas de suas militantes passaram a atuar em lutas mais gerais, deixando de lado as reivindicações mais relacionadas ao feminismo.

Em 1916, foi estabelecida uma polêmica nas páginas de $O$ Rebate, envolvendo Amélia Gomes (liderança feminina) e Ritoca Werneck. Ritoca propunha que as mulheres se dedicassem a questões puramente educacionais, como forma de capacitá-las para viver em sociedade, já Amélia, queria que as mulheres opinassem e se posicionassem sobre todos os assuntos, inclusive sobre a luta pela paz e o antimilitarismo (LONER, 2001).

A luta contra a guerra foi uma das maiores campanhas feitas pelos anarquistas. Eles atuaram através de grandes chamamentos para comícios, protestaram em mobilizações, realizaram passeatas e escreveram artigos. Ainda fundaram o Núcleo Popular Pró Paz, durante os anos de 1914 e 1915. Segundo Santos Barboza (apud LONER, 2001), em Pelotas a luta pela paz foi bastante articulada. No Congresso pela Paz no RJ, Pelotas teve a maior delegação, só perdendo para o Rio e São Paulo.

É preciso lembrar que esta não era uma posição cômoda, já que o Rio Grande do Sul tem forte tradição militarista. De outra forma, a guerra acabava consolidando sentimentos patrióticos, o que é um assunto difícil de ser contestado.

Ainda no ano de 1915, pelas páginas do jornal O Rebate, periódico de propriedade do federalista Frediano Trebbi, o qual se envolveu entre 1914 e 1923 (período de duração do jornal), em várias denúncias de abusos cometidos pela municipalidade ${ }^{8}$, assim é anunciado:

\footnotetext{
${ }^{7}$ Sobre o teatro anarquista de Pelotas, ver MIRANDA (2014).

${ }^{8}$ Miguel Ângelo da Cunha Filho, em seu Trabalho de Conclusão de Curso de História da UFPel, publicado no ano de 2011, escreveu sobre a disseminação da intolerância através da imprensa, abordando o caso do jornal $O$ Rebate. O jornal reproduz, em longas reportagens, a história de Francisca, menina de 6 anos que havia sido
}

Oficina do Historiador, Porto Alegre, EDIPUCRS, v. 8, n. 1, jan./jun. 2015, p.7-20. 
Convida-se aos jovens antimilitaristas a reunirem-se segunda, 15 de Novembro às 17 horas, na sede da Liga, a fim de fundar-se o grupo juventude anti-militarista, que terá por base combater o militar, esta fera humana que miseravelmente deixa na maior desgraça seus pais, seus irmãos, sua noiva, etc., e vai a matar a sangue frio seus semelhantes e até seu pai se for preciso, a bem daqueles que ficam em seus palácios resguardados de qualquer mal.

Em novembro do mesmo ano, Trebbi publicou o seguinte anúncio da Comissão Antimilitarista:

Jovens: É preciso que perdeis essa ignorância que vos leva a ponto de vestir a farda que é o emblema do assassino profissional; precisamos compreender que aquele que não nos fez mal não deve ter derramado seu sangue pelas nossas mãos e assim compreendermos, precisamos ler e analisar onde está a verdade. A Comissão.

Obviamente uma posição como essa causava comoção na cidade e mereceu reparo de outros periódicos locais. A questão é que Frediano Trebbi, mesmo não concordando com os libertários, dava-lhes liberdade para publicar seus contos, notícias e opiniões nas páginas do seu jornal, o que foi muito produtivo para ambos: os anarquistas tinham acesso a um meio de difusão de ideias eficiente e moderno para a época, como um jornal diário e Trebbi conseguiu, por meio de sua amizade com Santos Barboza, um dos principais nomes do grupo libertário na cidade, que este atuasse como seu correspondente no Rio de Janeiro, para onde foi em 1915 em diante, com as crônicas "guanabarinas" (sobre teatro, movimento operário e política) e com contos de sua lavra.

Mas o jornal $O$ Rebate havia nascido para causar polêmica, especialmente contra seus adversários políticos, do Partido Republicano Rio Grandense e o jornal Diário Popular, que os representava. Ao longo dos anos, diversas foram as discussões que envolveram os dois jornais, normalmente de origem política, mas que também podia alcançar vários outros ramos da vida cotidiana pelotense. Um dos mais famosos foi aquele da gripe espanhola, em que $O$ Rebate foi censurado, pela Intendência, pois esta não queria "intranquilizar" a população e $O$ Rebate resolveu publicar as listas de mortos. Como não pode publicá-las naquele momento,

doada a um grupo de ciganos. O que chama a atenção das matérias, no entanto, é o preconceito e discriminação do jornalista com relação a este conjunto de pessoas que vivia, na maior parte das vezes, de forma nômade.

Oficina do Historiador, Porto Alegre, EDIPUCRS, v. 8, n. 1, jan./jun. 2015, p.7-20. 
logo que foi levantada a interdição, ele se deu ao trabalho de listar uma a uma as mortes daqueles dias (LONER, 1998).

Outro momento muito tenso foi quando da invasão da cidade pelas tropas de Zeca Netto, em 1923, quando a multidão que acompanhou aquele líder em seu passeio pela cidade ficou a ponto de empastelar o Diário Popular (CALDAS, 1995). Mas como a invasão só durou um dia, depois da retirada de Netto, Trebbi teve que pedir asilo na casa do pai, representante italiano na cidade, para escapar de vinganças pessoais. Pouco depois, foi embora para o Rio de Janeiro e seu jornal deixou de circular.

Outro momento de profunda discordância foi o da cobertura da greve de 1917, quando o jornal deu todo o apoio à luta dos trabalhadores, contando a versão deles sobre acontecimentos e repressão. O Diário Popular, por seu turno, apoiou a intervenção policial na Liga. Até o final de sua existência, $O$ Rebate passou a lembrar anualmente "O massacre do dia 9 de agosto", data em que a Liga teve sua assembleia de greve atacada a tiros pela polícia, ocasionando a morte de um participante da mesma. (LONER, 1998).

Por fim, é necessário comentar sobre a mudança no cotidiano ocorrida na cidade, em função do episódio da gripe espanhola de 1918. Embora tenha ocorrido em várias regiões do Brasil e do mundo, ela transformou a rotina de Pelotas. Os eventos de gripe sempre tiveram presença marcante nos boletins relativos à saúde da população. A mudança, desta vez, foi a alta letalidade com que atingiu centenas de pessoas na cidade.

Alberto Coelho da Cunha, escrevente municipal por 40 anos, assim diz sobre o que aconteceu com a cidade em face da pandemia:

Com muito bom aspecto entrou, prosseguiu e prometia encerrar-se o ano de 1918, deixando-nos alimentar bem fundadas esperanças de conseguir Pelotas com a ajuda de Deus, bem invocado, a sua reabilitação sanitária, quando todos os cálculos desmoronam ante o ímpeto da invasão da pandemia gripal. Por princípios de outubro ela apresentou-se na cidade com ares benévolos de entidade traiçoeira que quer tomar pé e após o dia 20 começava a faina devastadora que havia de cobrir todos os lares de luto e encher de cadáveres as covas do cemitério. Só essa gripe arrebatou à população da cidade 353 vidas, cuja perda veio a figurar nos livros de registro civil.

O prédio da Intendência, que teve o seu expediente suspenso, transformou-se num grande quartel general contra a doença. Ali, praticavam-se os primeiros socorros, antes dos enfermos serem enviados para um Hospital de Isolamento temporário, que funcionava em um

Oficina do Historiador, Porto Alegre, EDIPUCRS, v. 8, n. 1, jan./jun. 2015, p.7-20. 
sobrado na Rua Marechal Floriano. Foram criadas ainda comissões que tinham como função visitar os domicílios, com o objetivo de identificar pessoas que necessitassem de auxílio.

Muitos doutores também adoeceram, tantos que o serviço clínico da Santa Casa, "[...] esteve quase que exclusivamente a cargo do Dr. Ariano de Carvalho, médico interno"9.

As estatísticas da época revelam diferentes números de mortos para a mesma enfermidade. Alberto Coelho da Cunha apontou 353 vítimas da gripe espanhola, em suas mais variadas formas, algumas delas relacionadas à tuberculose pulmonar. O Relatório da Santa Casa de Misericórdia ${ }^{10}$ noticiou a morte de 460 pessoas, também em diversas modalidades da doença. Jornais oposicionistas como $O$ Rebate, que teve muitas de suas matérias sobre a moléstia censuradas, fez um cálculo de mais de mil mortos, revelando que, em apenas um único cortiço, a reportagem do periódico havia encontrado 57 doentes, dos quais um só em pé ${ }^{11}$.

No jornal $O$ Rebate, de 5 de novembro de 1918, páginas 1 e 2 foi publicada a seguinte nota com o título de A Peste da Guerra em referência à gripe espanhola:

Seus funestos efeitos em Pelotas. Aumentam os números das vítimas. A epidemia alastra-se por toda a parte. Os socorros. Várias Notas. A miséria também conseguimos ver de perto. Percorremos a cidade toda, em todos os sentidos, por todos os cortiços infectos e imundos, na companhia de um fiscal da Intendência. Do que vimos, a pena de Zola só descreveu um resumo. É simplesmente desolador o estado de miséria do povo. Sem dinheiro, sem pão, sem assistência. Encontramos cortiços com 57 doentes, dos quais um só em pé, procurando socorrer os seus vizinhos, alcançandolhes alguns chás.

Quando o Brasil finalmente entra na guerra, ao final do conflito, o clima de patriotismo exacerba-se de tal forma que ocorrem episódios de depredação e incêndios contra estabelecimentos comerciais e clubes relacionados à cultura germânica, em Pelotas e na vizinha Rio Grande. Os jornais se prestam ao papel de favorecer este clima beligerante contra os alemães e outros estrangeiros, incitando os ânimos e, principalmente, dando espaço a uma série de boatos mal intencionados. Para se proteger, a comunidade alemã e seus descendentes

\footnotetext{
${ }^{9}$ Relatório da Santa Casa de Misericórdia da cidade de Pelotas, anos 1917-1918, p. 43. Sala do Rio Grande do Sul, BPP.

${ }^{10}$ Relatório da Santa Casa de Misericórdia da cidade de Pelotas, anos 1917-1918. Op. Cit., p. 44.

${ }^{11}$ Jornal O Rebate, dias 5 de novembro de 1918, p. 1 e 30 de dezembro de 1918, p. 1.
}

Oficina do Historiador, Porto Alegre, EDIPUCRS, v. 8, n. 1, jan./jun. 2015, p.7-20. 
nascidos no Brasil, mudam os nomes de alguns de seus clubes, abrasileirando-os ${ }^{12}$, num processo que vai encontrar maior desenvolvimento ainda durante a segunda guerra.

\section{Considerações Finais}

Ainda que a participação do Brasil não tenha sido relevante, se considerados outros países, em Pelotas o episódio da guerra serviu para fortalecer a organização dos trabalhadores, especialmente porque o nível de exploração de pessoas mais desprovidas de recursos financeiros chegou a um patamar alarmante.

Em função da guerra, fábricas e empresas fecharam suas portas, situação que provocou uma maior exploração dos trabalhadores, pois muitos perderam seus empregos ou tiveram seus salários diminuídos, fruto da crise mundial.

Dessa forma, foram anos muito duros para grandes camadas da população, que viram seus proventos e oportunidades de emprego diminuídas, ao mesmo tempo em que sofriam com o encarecimento de produtos que dependiam da importação. Por outro lado, mesmo produtos fabricados aqui, como a carne e os alimentos, subiram de preço devido à falta de controle das autoridades com a cesta básica do trabalhador. Igualmente, ocorreu com relação a um item que muito pesava no orçamento familiar, o aluguel. Foi devido a isso que a greve geral de 1917 se tornou popular, incorporando lutas e reivindicações que diziam respeito aos consumidores em geral e não apenas a salário e a horas de trabalho.

Nesta luta, bem como em todas as demais manifestações do período, observou-se uma divisão muito evidente entre os periódicos editados na cidade, cada um deles comprometido claramente com os interesses dos grupos e partidos políticos que defendiam.

Além do conflito mundial, eram comuns as epidemias nesse período, como a febre tifoide, varíola, peste bubônica, que atingiam, sobretudo, os mais pobres, justamente por serem os mais vulneráveis. Desse modo, a gripe espanhola, conforme abordado, trouxe medo e desesperança a uma população que pouco podia esperar do futuro. Note-se que até mesmo o

\footnotetext{
${ }^{12}$ O jornal $O$ Rebate de 5 de fevereiro de 1920, p. 3, cerca de dois anos após o término da Primeira Guerra Mundial, publica a notícia de que o Colégio Alemão, fundado em 1898, reabriria suas portas a partir de 1920 , com o nome de Colégio Internacional. A notícia enfatiza que todo "o ensino será ministrado na língua portuguesa e conforme os princípios mais modernos".
}

Oficina do Historiador, Porto Alegre, EDIPUCRS, v. 8, n. 1, jan./jun. 2015, p.7-20. 
presidente da República no momento, Rodrigues Alves, foi acometido pela doença, vindo a falecer.

Retornando ao início, espera-se ter demonstrado as dificuldades pelas quais passaram os moradores de Pelotas, especialmente suas camadas mais populares, com os problemas advindos da deflagração da guerra na Europa, mesmo que ela não incluísse diretamente o Brasil ou seu território. Num mundo que já era globalizado, por conta das necessidades de produtos industrializados e matérias primas, não foi possível ao país passar incólume por suas consequências.

Se a conjuntura proporcionou que trabalhadores se organizassem reivindicando por melhorias em sua vida cotidiana e pela construção da paz, por outro lado, aqueles anos foram um período muito difícil para a maioria da população brasileira, com carestia e dificuldades econômicas, a que se aliaram eventos climáticos e epidêmicos de grandes proporções, contribuindo para marcar aquela década como um momento sofrido e de grandes dificuldades para a população.

\section{Referências Bibliográficas}

ALONSO, José; BENETTI, Maria e BANDEIRA, Pedro. Crescimento econômico da região sul do Rio Grande do Sul: causas e perspectivas. Porto Alegre: FEE, 1994.

ANTUNES, Adriano. A Repercussão da Revolução Russa de 1917 nos jornais diários da República Velha no RS. História em Revista, Pelotas, v. 6, p. 115-131, 2000.

BARTZ, Frederico. O Horizonte vermelho: o impacto da revolução russa no movimento operário do Rio Grande do Sul: 1917-1920. Universidade Federal do Rio Grande do Sul. Dissertação (Mestrado em História). Porto Alegre, 2008.

BARTZ, Frederico. Movimento Operário e revolução social no Brasil: ideias revolucionárias e projetos políticos dos trabalhadores organizados do Rio de Janeiro, São Paulo, Recife e Porto Alegre entre 1917 e 1922. Universidade Federal do Rio Grande do Sul. Tese (Doutorado em História). Porto Alegre, 2014.

CALDAS, Pedro. Zeca Netto e a conquista de Pelotas. $2^{\text {a }}$ edição. São Leopoldo: EST, 1995.

CUNHA FILHO, Miguel Ângelo. A Disseminação da Intolerância através da Imprensa: o caso da menina Francisca. Pelotas, 2011. Trabalho de Conclusão de Curso (História - UFPel). FERRO, Marc. História da Primeira Guerra Mundial (1914-1918). Lisboa: Edições 70, 1992. GILL, Lorena. Labirintos ao redor das cidades: as vilas operárias em Pelotas (RS) 18901930. Revista Unisinos, v. 10, n. 1, p. 45-52, jan./abr. 2006.

GILL, Lorena. $O$ Mal do Século. Tuberculose, tuberculosos e políticas de saúde em Pelotas (RS) 1890-1930. Pelotas: EDUCAT, 2007.

HOBSBAWM, Eric. Era dos Extremos. O breve século XX (1914-1991). São Paulo: Companhia das Letras, 1995. 
LONER, Beatriz. Jornais pelotenses diários na República Velha. Ecos Revista. Pelotas, v. 2, n. 1, p. 5-34, abr. 1998.

LONER, Beatriz. Construção de classe. Operários de Pelotas e Rio Grande. Pelotas: Editora da UFPel, 2001.

LONER, Beatriz e AQUINI, Daniel. Verbete Economia. In: LONER, Beatriz; GILL, Lorena e MAGAlHÃES, Mario (Orgs.). Dicionário de História de Pelotas. Pelotas: Editora da UFPel, 2012.

LONER, Beatriz. O IV Congresso operário gaúcho e o ocaso do movimento anarquista no Rio Grande do Sul. Revista Patrimônio e Memória, v. 7, n. 1, p. 285-301, jun. 2011.

LUCA, Tânia. História dos, nos e por meio dos periódicos. In: PINSKY, Carla (Org.). Fontes Históricas. São Paulo: Contexto, 2010, p. 111- 153.

MAGAlHÃES, Mário Osório. Opulência e Cultura na Província de São Pedro do Rio Grande do Sul: um estudo sobre a História de Pelotas (1860-1890). Pelotas: Ed. UFPel: Coedição Livraria Mundial, 1993.

MIRANDA, Cássia. O teatro na voz operária: grupo teatral Cultura Social e o anarquismo em Pelotas, seus operários e suas palavras. Florianópolis, Universidade do Estado de Santa Catarina, Dissertação (Mestrado em Teatro), 2014.

OLIVEIRA, Leni. O início do fim da ferro carril e cais de Pelotas: o caso dos bondes na noite de 14 de dezembro de 1914. Monografia. Pelotas, 1997.

OLIVEIRA, Tiago Bernardon. Anarquismo, sindicatos e revolução no Brasil (1906-1936). Tese (doutorado em história). Universidade Federal Fluminense, Niterói. 2009.

PETERSEN, Silvia. Que a União Operária seja nossa pátria. Santa Maria: EDUFSM, 2001.

QUEIRÓS, César. O governo do Partido Republicano Rio-grandense e a questão social (1895-1919). Universidade Federal do Rio Grande do Sul. Dissertação (Mestrado em História). Porto Alegre, 2000.

QUEIRÓS, César. Estratégias e identidades: relações entre governo estadual, patrões e trabalhadores nas grandes greves da Primeira República em Porto Alegre ( 1917-1919). Porto Alegre. Tese (Doutorado em História) Universidade Federal do Rio Grande do Sul, 2012.

RÜDIGER, Francisco. Tendências do Jornalismo. Porto Alegre: Ed. Universidade/UFRGS, 1993.

TOLEDO, Edilene. Anarquismo e sindicalismo revolucionário. São Paulo: Perseu Abramo, 2004.

ARTIGO ENVIADO EM: 04/02/2015

ACEITO PARA PUBLICAÇÃO EM: 27/04/2015

Oficina do Historiador, Porto Alegre, EDIPUCRS, v. 8, n. 1, jan./jun. 2015, p.7-20. 